Outros Tempos, www.outrostempos.uema.br, ISSN 1808-8031, volume 03, p. 182-196 182

\title{
Peregrino no tempo: memórias poéticas de João Cabral de Melo Neto
}

\section{Fernanda Rodrigues Galve}

Bacharel em História pela Pontifícia Universidade Católica de São Paulo (PUC-SP)

Mestre em História pela Pontifícia Universidade de São Paulo (PUC-SP)

Resumo: Estudo sobre o poeta João Cabral de Melo Neto através de sua obra Morte e Vida Severina - Auto de Natal Pernambucano, de 1954, poema dramático que nos conduz ao fluxo do rio da vida severina e nos leva a refletir sobre questões sociais e históricas, que procuram levantar um retrato das condições e dos problemas do homem nordestino. Analisa-se, ainda, a junção entre história e literatura, onde a palavra poética apresenta tempo e memória.

Palavras -chave: Poesia, História, Tempo, Memória.

\begin{abstract}
Paper on the poet João Cabral de Melo Neto through his book Morte e Vida Severina, written in 1954, which is a dramatic poem that approaches the tough life of the people from the Northeast of Brazil and its social and historical aspects. The poem puts history and literature together, bringing us time and memory.
\end{abstract}

Keywords: Poem, History, Time and Memory. 


\title{
1. O poeta e o rio da vida
}

\author{
(...)E neste rio indigente, \\ sangue-lama que circula \\ entre cimento e esclerose \\ com sua marcha quase nula, \\ e na gente se estagna \\ nas mucosas deste rio \\ morrendo de apodrecer \\ vidas inteiras a fio, \\ poderias aprender que o homem \\ é sempre a melhor medida \\ Mas: que a medida do homem \\ não é a morte mas a vida.
}

João Cabral de Melo Neto (Pregão turístico do Recife).

Ao percorrer as páginas da obra mais conhecida de João Cabral de Melo Neto, Morte e vida Severina - Auto de Natal Pernambucano (1954-55), deparamo-nos com uma longa jornada.

O poeta João Cabral de Melo Neto, pernambucano, filho e neto de dono de engenho, "saltou para dentro da vida" no ano de 1920. Desde muito moço, este versejador, parente de Manuel Bandeira e de Gilberto Freyre, manifestou interesse pela palavra poética e pela leitura de cordéis.

João Cabral, em uma entrevista a José Carlos Vasconcelos, publicada no Diário de Lisboa em 16 de junho de 1966, sintetiza a influência da leitura do cordel com a obra Morte e vida Severina:

quando eu era menino, os trabalhadores do engenho de meu pai vinham me chamar: "Vamos à feira, diz que saiu um romance novo". E à noite era eu quem lia para eles...essas leituras devem ter influenciado o meu auto [Morte e vida severina];o conjunto de minha poesia é mais simples que a poesia popular, sem rimas; minhas estrofes são mais curtas, porque não quero "distrair" o leitor, mas, em se tratando de uma obra que pretende contar o povo e se contar para o povo, eu devia utilizar a forma mais adequada, que é o metro popular do romancero, sempre vivo. É a nossa sorte: nós, artistas de tradição ibérica, podemos recorrer a essa mistura de popular e erudito que vem das fontes. 
O poeta João Cabral surge em 1942, quando lança o livro Pedra do Sono e em 1946 ingressa no Departamento Cultural do Itamaraty, residindo assim em diferentes locais do mundo como Barcelona, Catalunha e em Londres.

No ano de 1952, João Cabral retorna ao Brasil para responder a um inquérito, onde é acusado de subversão. O diplomata Mário Calábria seria responsável pela denúncia de João Cabral como comunista (depois de interceptar uma carta a Paulo Cotrim, solicitando um artigo para uma revista do Partido Trabalhista Inglês), o que levou o poeta a ser desligado da diplomacia, só conseguindo a reintegração dois anos depois.

Seguindo este rio de suas memórias, o autor fechou este momento que viveu na década de 50 com a sua obra mais conhecida, Morte e vida Severina - Auto de Natal Pernambucano, a pedido de Maria Clara Machado, diretora do grupo teatral Tablado, que não pôde levar ao palco a peça. O Auto de Natal só foi encenado 10 anos depois, no TUCA - Teatro da Universidade Católica, em São Paulo.

Ao publicar "Duas águas", em 1956, o poeta incluiu "Morte e Vida" como poema. Esta composição literária consiste na inversão de uma peça para poema:

\footnotetext{
Maria Clara Machado, que dirigia o Tablado, me pediu um auto de Natal, o que não possibilita nenhuma originalidade. Qual é a obsessão de todo nordestino? O problema do retirante.(...) A Maria Clara não quis montar o espetáculo. Quando fui publicar Duas águas, poesia completa até 1956, e o livro estava pequeno, resolvi incluir o auto como poema. Tirei as marcações - entra, sai, faz, diz, essa coisa toda. Cada diálogo foi transmarcado com o tracinho, mas não se vê quem o está dizendo. É um monólogo diálogo. (...) (STEEN, 1981, P.99)
}

Por intermédio do seu olhar no mundo, João Cabral consegue transcrever em sua poesia o exercício rigoroso do trabalho com a palavra que busca a crítica social. É importante notar, ainda, que este versejador vê em Recife o que outros poetas, por estarem acostumados à cidade, não vêem. O poeta, assim, por ter se ausentado desta urbe por um longo período e, sobretudo, por ter vivido na Europa - principalmente em Sevilha -, singulariza a cidade e seus traços essenciais. Em uma reportagem feita sobre o poeta no jornal O popular de Goiânia em 22 de dezembro de 1981. João Cabral esclarece:

Morte e Vida Severina é minha experiência de infância, que guardo na memória que nunca sai da cabeça, sobretudo quando estava fora. O poema é o material de qualquer nordestino, é a reflexão sobre a realidade, sem outro compromisso que não seja com a verdade. 
Outros Tempos, www.outrostempos.uema.br, ISSN 1808-8031, volume 03, p. 182-196 185

João Cabral embrenha-se na realidade do contexto social de sua terra natal, Pernambuco, e flerta com a história social em vez de se recolher apenas ao território protegido da ficção.

Mesmo quando o poeta fala do seu tempo, da sua experiência de homem de hoje entre homens de hoje, ele o faz, enquanto poeta, de um modo que não é do senso comum, fortemente ideologizado, mas de outro, que ficou na memória infinitamente rica da linguagem.

João Cabral é um poeta que só trabalha em ferro forjado. É o poeta do concreto, pedreiro do verso, aquele que domina a matéria. A busca da razão na poesia não se restringe a uma poesia da razão, mas envolve uma ética da solidariedade, que é identificada com um movimento de mais profunda e por isso difusa religiosidade.

Sua poesia evidencia a temática social na tentativa de escrever aquilo que ele vê ou lembrou-se do que observou de Pernambuco. O poeta reencontra-se no Sertão, no Agreste, no Recife e procura denunciar e criticar o que enxerga mais claramente nas vivências sociais nordestinas.

Sua obra poética critica a realidade social extraindo imagens. Seu trabalho seletivo com a palavra faz-se na construção das imagens e dos fatos, pois não existe para ele poesia sem os acontecimentos (sem história).

Em sua poesia, João Cabral procura refletir sobre os tempos da memória, individual ou coletiva, valendo-se de lugares concretos para exprimi-los e materializá-los na forma de poema. Assim, o tempo perdido e re-encontrado pela memória que constrói, transforma e resgata a realidade e que nem sempre é muito úmida ou seca, como seu Nordeste.

A obra Morte e Vida é marcada pela tragicidade social do Nordeste. A sequiência progressiva de imagens é construída, de forma que extrema o sentido trágico dimensionado pelas impressões do real na memória.

Um poeta que é ao mesmo tempo pernambucano e cosmopolita. Um João Cabral que encontra o Nordeste da sua memória. Vive, assim, o poeta, o rio de suas reminiscências infantis e juvenis, de memória, numa época em que sua sensibilidade não podia reagir ao rio tal como, mais maduro com os anos, com a vida. 
Outros Tempos, www.outrostempos.uema.br, ISSN 1808-8031, volume 03, p. 182-196 186

Em 1930, filho de oligarquia de cana-de-açúcar decadente, João Cabral integra o momento histórico de desterro em direção à cidade e à modernidade. A realidade do Recife, a visão da diferença entre os retirantes fugitivos da seca e dos miseráveis habitantes dos manguezais com o contraste dos casarões e engenhos afetam o poeta e caracterizam a sua obra.

Este contexto que vai de 1930 a 1945 é de grandes transformações no Brasil, época de uma grande produção literária, que reflete um conturbado momento histórico: no âmbito internacional, vive-se a depressão econômica, o avanço do nazi-fascismo e a Segunda Guerra Mundial; já no âmbito interno, dá-se a ascensão de Getúlio Vargas, que integra a mudança de paradigma político de oligarquias da República para o populismo do Estado Novo.

A interlocução deixa de ser dos coronéis excluindo o povo, para um ditador que fala em nome e para o povo. Assim, o universo temático amplia-se e apresentam-se artistas preocupados com o destino dos homens.

As transformações vividas pelo país em 1930 e o questionamento das tradicionais oligarquias, os efeitos da crise econômica mundial, os choques ideológicos levantando uma posição mais definida formaram um cenário amplo e propício ao desenvolvimento caracterizado pela denúncia social, verdadeiro documento da realidade brasileira.

A partir de 1950, o poeta pernambucano apresenta uma poesia cada vez mais preocupada com a temática social. Sua primeira obra deste momento, $O$ cão sem plumas, seguido de $O$ rio ou a relação da viagem que faz o Capibaribe de sua nascente à cidade do Recife (1953) e finalmente Morte e Vida Severina Auto de Natal Pernambucano, todas falando da agudeza através do uso da palavra, da imagem do rio Capibaribe.

Com a evocação do rio Capibaribe, João Cabral adota o rio de sua infância e através de sua lembrança o drama da miséria nordestina, não o Nordeste de sua meninice, a Zona da Mata, mas o Nordeste do Sertão do retirante.

João Cabral problematiza o mundo real e exterior, conduzindo ao tempo real, com a preocupação de recuperar o momento perdido através da memória. Contudo, o poeta, por sua impossibilidade e sem perceber, integra sua vida a sua obra,onde sua memória determina, escolhe e aglutina sensações, tanto do presente quanto do passado para a construção de sua poesia. 
Portanto, João Cabral, no processo de produção de sua poesia, preza o seu mundo, sua realidade e as suas raízes. Para Cabral: "O poema é o eco, muitas vezes imediato da experiência. O poema traduz a experiência, transcreve e transmite." (OLIVEIRA, 1992, p.5) Com este eco, o poeta constrói uma poesia crítica, onde a composição é planejada de fora para dentro, como uma casa. $\mathrm{O}$ universo das palavras na poesia possibilita significados, coerência ao mundo. Os poemas de João Cabral voltam-se para o universo dos objetos, das paisagens, dos fatos sociais e culturais.

O tempo histórico é sempre plural: são várias as temporalidades em que vive a consciência do poeta e que "atuam eficazmente na rede de conotação do seu discurso." (BOSI,2000, p.142) A poesia em si já é multidimensional e para sua construção constitui-se de pensamento, imagem e ritmo próprios que se interligam como raízes de uma mesma árvore.

Essa árvore possui o mesmo tronco, o mesmo saber, que com o passar da história constitui-se de valores, consciência e anseios em eterna transformação. Em seus ramos guarda as lembranças, crenças e esperanças que são mutáveis e se renovam a cada nova estação, como a poesia. Assim:

Ler a realidade pelo poema é sempre refazer a História. Por isso, metalinguagem e História em sua obra, interpenetram-se tão fecundamente. A historicidade de sua poesia está sempre apontando para dois espaços fundamentais, isto é, o de sua circunstância social e histórica. (BARBOSA, 1986, p.107)

A palavra poética tenta entender a natureza do tempo que articula arranjos próprios para a sua construção. A obra de João Cabral não se desfaz, um só momento, de uma intensa historicidade. A História -pluralidade de formas- mergulha no universo da palavra poética. Ler a realidade pelo poema é sempre refazer a história.

O poema têm um papel fundamental como um documento que, além de registrar temporalidades, nos fala ao coração através do uso da palavra, pois o poema (a Arte) é vida produtiva, vida ativa, vida sensível. Não é um poema produzido por inspiração.

Pelo contrário, ao lermos a obra de João Cabral, percebemos que esta palavra não existe. "Daí sua poesia freqüentemente confessar-se como um ponto de vista (histórico) sobre a linguagem, e não como um neutro espaço de onde as palavras emanariam resgatadas em uma pureza original.”(SECCHIN, 1985, P.36) 


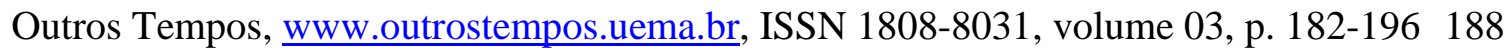

O que há é a palavra, trabalho, pesquisa e a utilização da bagagem cultural e de vivências. Ao ler sua poesia, o autor parece presente de corpo inteiro e com grande habilidade técnica.

Para o poeta, o tempo pode ser sentido em sua amplitude, ao utilizar-se da substância viva e física que possui a vida. Tempo que passou, correu e se depositou. Sua palavra poética possui relações densas com os tempos sociais, reflete a história de seu pensamento crítico e do trabalho com sua memória. Isto ocorre não como uma máquina, de forma homogênea, e sim como experiência humana.

O poeta que trabalha com tema dramático é um sujeito produtor, que conhece e não cria universalidades, recorta da realidade aquilo que move a vida cotidiana e a vivência-mundo do saber no mundo do ser. Nessa perspectiva, a instância poética parece tirar do passado e da memória o direito à existência.

Assim, o poeta não vive em uma outra história distante ou alheia à história da formação social em que escreve. Na poesia, cumpre-se o presente sem margens do tempo, de um tempo originalmente social.

O tempo é o modo pelo qual o poeta tece e formula conexões com a tradição e define trajetórias através de movimentos cíclicos. O poeta reproduz a memória histórica a partir da trama engendrada por um fato, a seca, que determina o desenrolar da história.

O poeta João Cabral apresenta suas memórias poéticas e recompõe a cidade, reconstruindo o Recife, uma cidade trazida da infância dos engenhos e das histórias conhecidas aprendidas através da leitura de cordéis, sinônimo de origem e síntese das representações urbanas que marcam a memória do poeta.

Enfim, a letra assume o lugar da voz como mecanismo possível de recuperação de um tempo passado que gradativamente se perde, rompe-se frente às artimanhas modernas que refutam a tradição e defendem a importância do novo. 


\section{O tempo e o rio}

A cidade do Recife é constituída por um enorme mosaico de cores, cheiros e sentimentos, uma cidade que, mesmo com o caos urbano, reflexo da síntese das múltiplas expressões culturais, consegue ao mesmo tempo aspirar e a abolir os efeitos desnorteadores, dando uma marca inquestionável à cidade, sua paisagem natural, seus acidentes geográficos e seus rios.

O rio Capibaribe, em tupi, rio das capivaras, aproxima povos e culturas através de seu percurso. Esta idéia é reiterada por Josué de Castro:

Heródoto dizia que o Egito era um dom do Nilo. Tudo lá era fruto das águas: terra, economia e religião. Também o Recife - essa pitoresca cidade, discreta e envolvente - é um dom dos rios. Rios que deram origem à cidade e foram importantes fatores de sua história. (CASTRO,1957, p.257)

O Rio Capibaribe que nasce na Serra dos Jacararás, nos Cariris Velhos, percorre um longo caminho encontrando cidades e vilas, contando simbolicamente todas as aventuras da vida no sertão. Em alguns momentos apresenta-se como um rio humilde, um escasso fio de água, quando é tempo de seca e de necessidade, aqui, o rio identificado como o homem do nordeste, tem uma sina a cumprir - "pernas que não caminham":

Capibaribe contraditório amargamente irônico...cheio de contrastes gritantes, muda extraordinariamente de fisionomia da aristocrática Madalena ou Ponte d’Uchoa, aos Coelhos e Joana Bezerra, povoados de tremenda miséria, daí versos duros e cruéis de João Cabral. (VAMIREH, 1959, p.119)

No Auto de Natal Pernambucano, o rio Capibaribe é guia, cenário e o nosso fio condutor para esta grande jornada. Rio espesso, amistoso e confidente, trajeto que nosso retirante Severino tem medo de perder, retirante que aprende com a experiência e sabe que ao seguir este grande rio pode chegar à vida:

$$
\begin{aligned}
& \text { Não desejo emaranhar } \\
& \text { o fio de minha linha } \\
& \text { nem que se enrede no pêlo } \\
& \text { hirsuto desta caatinga. } \\
& \text { Pensei que seguindo o rio } \\
& \text { eu jamais me perderia: } \\
& \text { ele é o caminho mais certo, }
\end{aligned}
$$




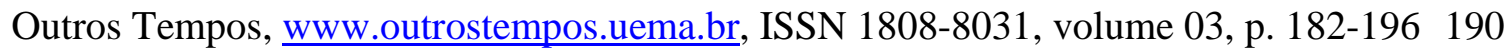

$$
\begin{aligned}
& \text { de todos o melhor guia } \\
& \text { (...)Mas como segui-lo agora } \\
& \text { que interrompeu a descida? } \\
& \text { Vejo que o Capibaribe, } \\
& \text { como os rios lá de cima, } \\
& \text { é tão pobre que nem sempre } \\
& \text { pode cumprir sua sina } \\
& \text { e no verão também corta, } \\
& \text { com pernas que não caminham. }
\end{aligned}
$$

Durante a sua descida, o rio reflete paisagens diferentes, cada vez mais acolhedoras. Por estas novas paisagens, suas águas encontram novos afluentes: Ribeiro do Arroz, Ribeiro do Urubu, da Grota e da Fenda, do Mel e da Cachaça, do Pau de Arara, da Pedra Tapada entre outros rios, que, juntos, também contam suas histórias.

O rio Capibaribe, seco no Agreste, grandioso na cidade, delicado na nascente, corre para o mar e em seu caminho produz ou encaminha vidas. Ao chegar na cidade do Recife, o Capibaribe encontra seu grande amigo em um grande abraço, o rio Beberibe.

Estes dois rios guias e aventureiros em estado de boemia se avolumam, perdem o rumo, formam canais, mangues onde se acomoda Recife e onde, como bons e velhos amigos, resumem suas aventuras heróicas até o grande encontro com o Atlântico.

Em Morte e vida Severina, o rio Capibaribe é uma personagem marcante que simboliza tanto o local de esconderijo e o local de morte e de vida.

O rio na obra de João Cabral pode ser entendido como o tempo, tempo de reflexão, de esperança e ou medida para a história.

O poeta, nesta obra, apresenta ao leitor uma crítica sobre o homem que vive apenas o momento rotineiro, sem sal, mas essencial. Vive para apenas sobreviver, e apresenta-nos um homem, Severino, sonhador e esperançoso, homem que têm poderes para transformar o tempo, construir a história.

Para entendermos melhor esta idéia, voltemos às palavras de Heráclito: não se pode entrar duas vezes no mesmo rio. Com isto percebemos que a realidade constantemente se altera, como o tempo, como o rio, como o homem. Ou seja, tudo transforma-se a cada instante.

O tempo remete-nos a processo, organização, controle, rítmo. Através deste tempo finíssimo e transparente é que percorre a História. O tempo é preenchido com a matéria viva, o homem, que deve habitá-lo com olhar para o futuro, quando então o tempo já estará 
morto, porém habitado e vivo na memória. Embora as imagens e as palavras ocorram no agora, sabemos que eles pertencem a um momento que não existe mais.

Para o poeta, o tempo pode ser sentido em sua amplitude, ao utilizar-se da substância viva e física que possui a vida. Se a vida esta vazia, o tempo torna-se rotina e os cinco sentidos acostumam-se com o viver. Este tempo descrito é rotineiro, lento e simples.

Tempo sensível e perceptível, pois não muda, e que pode, possivelmente, ser comparado a um bicho, que pelo costume de tê-lo ao lado torna-se hábito.

Para João Cabral, este tempo rotineiro aparece na poesia através da ladainha e do rosário:

\author{
Antes de sair de casa \\ aprendi a ladainha \\ as vilas que vou passar \\ $\mathrm{Na}$ minha longa descida. \\ Sei que há muitas vilas grandes, \\ Cidades que elas são ditas; \\ Sei que há simples arruados, \\ Sei que há vilas pequeninas, \\ todas formam um rosário \\ cujas contas fossem vilas, \\ todas formando um rosário \\ de que a estrada fosse a linha. \\ Devo rezar tal rosário \\ Até o mar onde termina, \\ Saltando de conta em conta, \\ Passando de vila em vila.
}

O tempo demonstra sua existência na simplicidade de seu passar, de seu percurso, expressando-se em formas. Tempo que segue o ritmo da ladainha e as contas de um rosário. Tempo igual repetitivo, se não fosse a diferença entre as vilas e arruados, onde a vida transforma-se a cada instante.

Portanto, o tempo pode ser medido tanto pelas batidas do coração quanto pela da regra. Os gregos perceberam esta diferença e designaram duas palavras distintas para utilizarem no dia-dia ao indicar esses dois tempos: Chronos e Kairós.

O tempo Chronos é dividido em espaços iguais como horas, minutos, segundos. Oscila com total indiferença à vida e à morte, a tristeza e alegria. É o tempo sem surpresas, rotineiro. O tempo Chronos é dividido em espaços iguais, como horas, minutos e segundos. Oscila com total indiferença à vida e à morte, à tristeza e à alegria. É um tempo sem surpresas, rotineiro. Já o tempo Kairós é medido pelas batidas do coração, sem precisão e 
regras. Suas batidas flutuam ao ritmo da vida e da morte. O tempo do coração varia conforme a imaginação e transforma-se com o medo e a tropeça. Ele vive de surpresas.

Chronos é o tempo do dever rotineiro, do corpo engaiolado. Esta jaula é frágil e transparente como o vidro, mas em seu interior vive um bicho, o qual independentemente do local da gaiola contêm alada palpitação - tempo kairós -, que possibilita imaginar para "sentir-se existente."

Destes momentos variáveis transcorre a vida e seus sonhos. Este tempo do rosário é um momento rotineiro, compasso regrado, como a ladainha e o rosário por demais precisos e contínuos. Contudo, o improvável pode ocorrer, por algum rompimento deste tempo surge no homem,e:

\author{
Desde que estou retirando \\ Só a morte vejo ativa, \\ Só a morte deparei \\ E as vezes até festiva; \\ Só morte tem encontrado \\ Quem pensava encontrar vida, \\ E o pouco que não foi morte \\ Foi de vida severina \\ (aquela vida que é menos \\ vivida que defendida, \\ e é ainda mais severina \\ para o homem que retira).
}

Seguindo esta análise, esta obra poética é composta de estruturas cíclicas em que coexistem os momentos Chronos e Kairós. São múltiplos os aspectos que demonstram o tempo e a história por intermédio destes ciclos. Os principais são o rio Capibaribe e o mar, a morte e a vida.

Estes ciclos envolvem o homem e o tempo e marcam a transformação, constituindo um exemplo de uma trilha possível e prevista. Os argumentos que fundamentam esta idéia na poesia desenrolam-se em um tempo em que a ação dos afetos e da representação produz uma lógica própria, capaz de viabilizar construções equivalentes e belamente ordenadas, conforme afirma Vico ao estudar a lógica poética: 
uma série de regressos. Não há puros regressos, nunca se regressa ao ponto de partida. É a divina providência que conduz o homem para cima, o que implica uma sucessão de renascimentos ou de regenerações, à maneira de Fênix.(VICO,1999, P.130)

Um dos ciclos importantes do poema de João Cabral consiste na inversão do seu título. A palavra "morte" antes da palavra "vida" toma significado especial. A morte a que o poeta se refere é a morte social, e não somente a individual. João Cabral esclarece esta idéia em uma entrevista concedida ao poeta Sebastião Uchôa:

[...] Nesse meu livro [Agrestes] eu narro uma conversa com Lopez Ibor, que era o grande psiquiatra de Madri quando eu estava lá. A mulher de um amigo meu da embaixada se tratava com López Ibor. Esse amigo me disse: "eu acho que você deveria ir ver Lopez Ibor." Como eu estava meio angustiado, concordei. O sujeito era extraordinário. López Ibor me disse: "Eu sei que o senhor escreve. O senhor me empresta um livro seu?" Eu perguntei: "o senhor lê português?" E ele: "Ah, leio.” Eu dei para ele Duas águas, que era, naquele tempo, minhas poesias completas. Na vez que eu voltei lá, ele me disse: "Eu fiquei impressionado como o senhor fala na morte." Então, falei: "Doutor López Ibor, o senhor está se referindo a Morte e vida severina, esse tipo de coisa. A morte de que falo não é a morte individual, rilkeana: é a morte social." (Athayde,1998, P.61)

A poeta versa sobre a vida, a história e a beleza do novo. E na condição severina da morte é o nascer de uma nova vida. A imagem da morte e da vida é estabelecida pelo rio Capibaribe e pelos homens que nele se fundem.

João Cabral compõe a imagem da morte no seu processo social. Esta morte do definhamento, da seca que desidrata gradativamente. Nessas condições, a única forma de vida é a presença do rio Capibaribe, um rio que, no início da jornada, apresenta-se aparentemente também morto, sem água.

A morte é a imagem da não-identidade do humano no homem que está vivo, como natureza degradada fisicamente, emocionalmente e mentalmente. Este ciclo de morte e vida é apresentado no início da jornada como uma imagem dramática deste cotidiano de adaptações e de desventuras humanas. Sob um outro ângulo, o poema transforma a morte em geradora de uma nova vida.

O homem Severino, carente de tudo e de morte matada, cria vida e história. Morrer e viver como classe severina é mais que viver e morrer. È fazer exemplo da morte à necessidade da vida, o horizonte da história.

A vida, em sua imanência, possui dinâmica própria, e o Auto de Natal Pernambucano, recoloca para os severinos uma lição de esperança. Mesmo vivendo em 
Outros Tempos, www.outrostempos.uema.br, ISSN 1808-8031, volume 03, p. 182-196 194

condições miseráveis, esta esperança, que identifica a cada ser, pode experimentar um salto "para dentro da vida", um limiar da história como um novo começo.

No que se refere à cultura, segunda extensão que se pode utilizar para analisar o deambulatório abordado na obra de João Cabral, é notada durante o processo de permanência desta religiosidade presente em Severino. Este retirante, ao chegar à cidade grande, é constituído de uma intensa religiosidade e de costumes que dificilmente serão transformados, mas provavelmente serão adaptados. $\mathrm{O}$ texto funciona como uma concepção da vida e do mundo que é aquela mesma oferecida pela cultura.

Nesse sentido, pode-se afirmar que a obra Morte e vida Severina é parte da sociedade, que perpassa e se constitui pela soma do inter-relacionamento do costume com a prática social. Estes discursos múltiplos oferecem mediações e reflexões sobre o popular como uma forma de luta e de resistência desenvolvidas pelo autor e estabelecidas nas relações de uns com os outros, com seus "outros" e com suas próprias condições de vida, no movimento de conter e resistir. Assim,a cultura é atribuída, em parte, ao campo social, ao qual está incorporada, e às práticas, as quais articula e é chamada a ecoar e a transformar.

João Cabral apresenta esta resistência no Auto a partir do que o retirante guarda dentro de si (suas raízes) e do seu encontro com a "outra" cultura da cidade. Isto ocorre na permanência (tradição) com o que Severino leva com suas experiências no sertão.

Ao longo do tempo, ocorre uma rápida destruição dos estilos específicos de vida e sua transformação em algo novo. Severino define sua existência na categoria da exclusão tanto por intermédio de seu comportamento, quanto por meio da sociedade que o rejeita.

João Cabral faz um poema preocupado com as tradições idealizadas para o Nordeste e as submete à crítica. A literatura, assim, propicia um traço de um quadro da vida social no tempo da convenção de um olhar de um mundo visto de baixo.

Do ponto de vista social, o Auto de Natal representa algo mais que apenas uma imagem da alteração social do Recife. A obra aprofunda raízes nessa tradição e procura mostrar como esta cultura pode ser modificada criticamente.

Enfim, a obra Morte e vida Severina é escrita com o uso de palavras "magras e ossudas", servindo para reforçar o desapego daquela vida, a provação daquela região, onde 
Outros Tempos, www.outrostempos.uema.br, ISSN 1808-8031, volume 03, p. 182-196 195

o rio "jamais espelha o céu”, desta angústia, deste vazio que permanece inalterado. João Cabral não nos mostra a pobreza e a tristeza da vida, mas sim a riqueza que nos falta.

Bibliografia

ATHAYDE, Félix de.Idéias fixas de João Cabral de Melo Neto. Rio de Janeiro: Nova Fronteira, 1998.

BARBOSA, João Alexandre. Balanço de João Cabral de Melo Neto. In: Ilusões da Modernidade: notas sobre a historicidade da lírica moderna, São Paulo: Perspectiva, 1986 .

BOSI, Alfredo.O ser e o tempo da poesia. São Paulo: Companhia das Letras, 2000.

CASTRO, Josué de. Documentário do Nordeste. São Paulo: Brasiliense, 1957.

MELO NETO, João Cabral de. Obra completa. Rio de Janeiro: Nova Aguilar,1986.

OLIVEIRA, Erson Martins de. Morte e vida em João Cabral. In: PUC viva, ano II- $\mathrm{n}^{\circ} 7$ dezembro de 1999.

SECCHIN, Antonio Carlos. João Cabral: a poesia do menos. São Paulo: Duas Cidades/INL;Fundação Nacional Pró memória, 1985.

STEEN, Edla Van. João Cabral de Melo Neto. In: Viver \& escrever. Porto Alegre: L\&PM, 1981. v.1.

TENÓRIO,Waldecy. A bailadora Andaluza. São Paulo: Ateliê Editorial; Fapesp, 1996.

VAMIREH, Chacom. O Capibaribe e o Recife - história social e sentimental de um rio. Recife: Secretaria de Educação e Cultura de Pernambuco, 1959. 
Outros Tempos, www.outrostempos.uema.br, ISSN 1808-8031, volume 03, p. 182-196 196 VICO, Giambattista. A ciência nova. Rio de Janeiro: Record. 1999. 